\title{
DIDÁTICA GERAL E DIDÁTICAS ESPECÍFICAS: PONTOS PARA REFLEXÃO
}

\author{
GENERAL AND SPECIFIC DIDACTICS: POINTS FOR REFLECTION \\ DIDÁCTICA GENERAL Y DIDÁCTICAS ESPECÍFICAS: PUNTOS PARA REFLEXIÓN
}

IIma Passos Alencastro Veiga*

\begin{abstract}
Resumo: O artigo situa-se no polêmico campo que debate a exclusão da Didática Geral ou Fundamental dos cursos de Licenciatura e o fortalecimento das diversas didáticas específicas, o que tem provocado a desarticulação entre o geral e o particular. Observa-se que não se trata de defender a existência de uma em detrimento da outra, mas de adotar-se uma abordagem integradora e problematizadora do papel da escola, a ação de ensinar, o processo de aprendizagem, a prática da organização colaborativa da aula e as questões da seleção do conhecimento, da metodologia e das práticas avaliativas.
\end{abstract}

Palavras-chave: Didática. Didática Geral. Didáticas Específicas.

\begin{abstract}
This article is located in the controversial field that discusses the exclusion of the General or Fundamental Didactics of undergraduate courses and the strengthening of specific didactics, which has caused the disarticulation between the general and the particular. It is observed that it is not a question of defending the existence of one to the detriment of the other, but of adopting an integrative and problematizing approach on the role of the school, the action of teaching, the learning process, the practice of the collaborative class organization and the questions about knowledge selection, methodology and evaluation practices.
\end{abstract}

Palavras-chave: Didactic. Fundamental Didactic. Specific Didactic.

Resumen: El artículo se sitúa en el polémico campo que debate la exclusión de la Didáctica General o Fundamental de los cursos de Licenciatura y el fortalecimiento de las diversas didácticas específicas, lo que tiene provocado la desarticulación entre lo general y lo particular. Se observa que no se trata de defender la existencia de una en detrimento de la otra, pero de adoptarse un abordaje integrador y problematizador del papel de la escuela, la acción de enseñar, el proceso de aprendizaje, la práctica de la organización colaborativa de la clase y las cuestiones de la selección del conocimiento, de la metodología y de las prácticas evaluativas.

Palavras-chave: Didátcica. Didáctica General. Didácticas específicas.

* Professora Titular Emérita da FE/UnB 


\section{Introdução}

O tema deste artigo sobre o qual tenho me dedicado ultimamente está sendo impulsionado pelas discussões polêmicas sobre a exclusão da Didática Geral ou Fundamental dos cursos de licenciatura e o fortalecimento das diversas didáticas específicas o que tem provocado a desarticulação entre o geral e o particular. É evidente que não se trata de discutir a existência de uma em detrimento da outra e nem ao contrário. Trata-se de uma abordagem integradora e problematizadora do papel da escola, a ação de ensinar, o processo de aprendizagem, a prática da organização colaborativa da aula e as questões da seleção do conhecimento, da metodologia e das práticas avaliativas.

A centralidade do porquê, o quê e o como ensinar que delineou o processo didático é focada em articulação com o ato pedagógico e com todas as áreas do conhecimento que estruturam os cursos de formação de professores. Assim, o projeto de formação de professores não pode organizar-se de forma aditiva, mas sob a perspectiva da integração em torno do eixo estruturante que é a prática profissional em contexto (ROLDÃO, 2004). Isso significa que a delimitação epistemológica leva em conta o saber organizar o processo didático em suas diferentes dimensões: ensinar, aprender, pesquisar e avaliar, bem como uma clara centralidade nas dimensões dos conhecimentos específicos.

Então, vale indagar: o que será necessário para orientar os nossos propósitos, a fim de concretizar a prática da integração entre a Didática Geral ou Fundamental e as didáticas específicas? Talvez seja possível delimitar alguns pontos para reflexão, que não esgotam as respostas possíveis, mas que podem contribuir para a ação integradora, nucleares entre o geral e o específico. A resposta à questão levantada passa pelo menos por dois grupos diferentes de ponderações: as de natureza epistemológica e outras metodológicas e que, colocadas em prática, poderão facilitar a construção das didáticas específicas em diferentes campos científicos integradas à didática de cunho geral. Trata-se de áreas de estudo e pesquisa, de conhecimento curricular que estão se reconfigurando.

Refletir a Didática Geral e as específicas significa entendê-las sob a ótica de alguns autores, com o intuito de ressaltar os pontos relevantes, na tentativa de fortalecer a natureza e características de cada uma delas e suas conexões com o campo epistemológico da Pedagogia, as concepções de ensino no âmbito geral, de ensino específico e as experiências dos professores. Significa também analisar a escola de hoje que é responsabilizada por uma ampliada gama de funções, incluindo também a de prover serviços sociais. A escola deve ser concebida como espaço-tempo de diálogos democráticos, de compromisso pessoal e social com a cidadania e a formação humana.

\section{A Didática Geral e as didáticas específicas nas concepções dos autores}

Para Bedoya (2005), a didática especial é denominada assim porque deve corresponder a cada ciência ou disciplina específica, objeto de um determinado ensino. Isto supõe que toda ciência ou disciplina teria implícitas estratégias didáticas ao lado das científicas ou investigativas para serem concretizadas em aula. Há uma identificação da didática com o conhecimento específico. O autor afirma:

A didática das disciplinas exige ou implica um processo incessante de investigação e discussão - replanejamento e construção constantes porque os problemas, para serem postos em prática, não como uma mera montagem instrumental e operativa, 
exigem a confrontação epistemológica e interdisciplinar (Ibid, p. 181).

Por essa ótica, a didática específica não constitui um conjunto de rotinas predefinidas, pois o processo didático na sala de aula reproduz e ao mesmo tempo constrói novos espaços. É uma didática que reinventa a prática pedagógica por intermédio da crítica do objeto estudado, isto é, o ensino no contexto da educação e do posicionamento político que direciona a ação do professor e dos alunos.

Libâneo (2008) busca a unidade entre uma Didática Geral do ensino e as metodologias específicas. Defende a unidade e a interdependência por meio da relação indissociável entre "as questões pedagógico-didáticas e a questão epistemológica” (p. 63). Sob esta ótica, o pedagógico está sempre em conexão com o epistemológico.

$\mathrm{O}$ autor discute quatro argumentos a favor da integração entre Didática e didáticas específicas ou especiais, sinteticamente apresentados a seguir:

a) a didática e as didáticas especiais têm o ensino como objeto de estudo e de pesquisa. Elas têm as mesmas tarefas, ou seja, explicitar o processo docente do conhecimento;

b) as formas de ensinar dependem das formas de aprender, pois o elemento nuclear é a aprendizagem do aluno;

c) aprender é desenvolver as capacidades cognitivas do estudante de modo que domine conceitos, forme esquemas mentais, raciocine logicamente, argumente e solucione problemas etc.;

d) a didática e as didáticas especiais, vinculadas à pedagogia, atribuem uma intencionalidade formativa ao ato de ensinar.

Nesse sentido, a didática e as didáticas específicas são interdependentes, uma vez que o objeto de estudo de ambas é o ensino.

\section{Elementos estruturantes das didáticas específicas}

Para conferir mais clareza ao texto, opta-se por apresentar os elementos em subitens, considerando-os separadamente, para articulá-los na conclusão. Portanto, a seguir, relacionam-se os elementos estruturantes que caracterizam uma didática especial: configuração contextual, fato epistemológico, saberes e linguagens específicas, atribuições de significados, intencionalidades e delimitação procedimental. O objetivo é analisar os elementos necessários à configuração de didáticas específicas considerando a natureza e a especificidade dos campos epistemológicos dos componentes curriculares ou áreas de conhecimento.

\section{Configuração contextual}

Ao recorrer a esta expressão, ressalta-se a importância deste elemento estruturante de uma didática específica no sentido de se compreenderem os vínculos do campo epistemológico, sua prática com a prática social mais ampla. Isto significa vincular os conhecimentos específicos curriculares e de cada componente curricular às finalidades sociais mais amplas. Significa pensar o objetivo de estudo no contexto social e qual o papel desse contexto.

\section{Fato epistemológico}

Promover novos fatos epistemológicos no sentido de atribuir significado ao conhecimento apontando suas relações, observando suas correlações e nexos. Um determinado conhecimento, conteúdo curricular disciplinar ou temático se torna fato epistemológico no âmbito de seu campo científico, quando são examinadas as características e 
as configurações do objeto de estudo sob diferentes dimensões: científica, pedagógica, político-social, econômica, histórica, geográfica, entre outras.

\section{Os saberes e as linguagens dos campos epistemológicos.}

A compreensão de saber implica a de sujeito de atividade do sujeito, de relação do sujeito com ele mesmo, de relação desse sujeito com os outros (que coconstroem, controlam, validam, partilham esse saber) (CHARLOT, 200). Não há saber em si, o saber é, portanto, uma relação do sujeito com o mundo, com ele mesmo e com os outros. O saber se desenvolve em constante movimento e em diálogo.

Barth (1997) ao discutir sobre os saberes apresenta as seguintes características: estruturado, evolutivo, cultural, contextualizado e objetivo.

O saber estruturado não existe sem o real. O interesse é perceber ao mesmo tempo os aspectos abstrato e concreto por meio da comparação dos dois. Assim, é oportuno estabelecer o elo entre o saber a ser ensinado e o contexto concreto.

O saber evolutivo não tem fim, é sempre provisório. A idade não é o fator determinante das nossas concepções, mas, como afirma o autor, "número de encontros" que tivemos com um determinado saber, bem como a qualidade da ajuda que tivemos com um determinado saber para interpretá-lo.

O saber cultural envolve o saber pessoal bem como o tempo e a experiência, abrangendo a interação com os outros “membros da nossa cultura” (ibid). É um saber partilhado que evolui e não existe de modo isolado num indivíduo.
O saber contextualizado surge em circunstâncias simultâneas afetivas, cognitivas e sociais. Este contexto é que lhe irá dar sentido -ou não - e que continuará a influenciá-lo. O autor apresenta quatro categorias para estabelecer a relação do contexto com o saber:
a) o saber está associado ao seu contexto;
b) o saber é confundido com o seu contexto;
c) o saber é diluído por um aspecto domi- nante do seu contexto;
d) o saber é induzido pelo seu contexto (Ibid).

É importante ressaltar que as categorias orientadas pelos termos "associado”, “confundido”, “diluído” e “induzido” dão a conotação de que os saberes devem ser analisados pelas didáticas específicas. Os saberes não são algo que permeiam o espaço sem relação com o mundo.

O saber afetivo é carregado de afetividade, de emoção e influência. Não podemos confundir o saber com a emoção na interpretação da realidade de forma subjetiva. A emoção, a afetividade, nossas atitudes e valores influenciam a nossa maneira de apreender a realidade e o modo de apreendermos a nós próprios.

Por isso, compreender os saberes dos campos epistemológicos para gerar didáticas específicas é necessário; vê-los como processo que requer uma permanente configuração de cada momento de construção e apreensão do saber. O trabalho docente acontece em uma relação que envolve os dois sujeitos: professor e estudante mediada pelos diferentes saberes.

A linguagem, em seu sentido mais amplo, é um dos elementos essenciais à vida contemporânea e às ciências. A linguagem expressa significações e, por esse motivo, é muito importante considerar a linguagem específica de cada campo científico como 
elemento estruturante da didática específica. A construção das didáticas específicas implica, portanto, compreender "linguagens” da medicina, da odontologia, do direito, da administração, das ciências da computação, da matemática, da pedagogia, da psicologia, da biologia, da história, das artes e outras mais. As linguagens específicas expressam os conhecimentos de cada campo científico.

O emprego da linguagem contribui para o processo de formação e transformação do sujeito, no caso o estudante, tanto nos seus modos de perceber, suas formas de pensamento e ação, quanto em seus aspectos subjetivos. Em consequência, transformará também o mundo desses estudantes que, ao darem novos sentidos e significados, modificam a própria linguagem do campo epistemológico. No fundo, isto significa desenvolver a capacidade do estudante para um raciocínio globalizante e integrador.

Qualquer saber, entendido como linguagem, organizada e fundamentada no contexto de um campo específico, é uma prática social, pois nela estão inseridos valores e significados atribuídos aos sujeitos e à sociedade que a constrói e que nela se ocupam.

\section{As atribuições de significados}

O quarto elemento estruturante que se propõe procura atribuir significados ao conhecimento, objetivando a compreensão do porquê dos conceitos. Nesse sentido, as informações são transformadas em conhecimentos e conceitos que podem ser transferidos a outras situações. A didática de um determinado campo epistemológico deve produzir uma aprendizagem que leve os alunos a transformarem e ao mesmo tempo torná-los capazes de atribuir significações ao que aprenderam, transferindo o conhecimento e saberes apreendidos, produzido e assimilado para outras situações educativas e, assim, fortalecer a capacidade de distinguir os conhecimentos essenciais, fundamentais dos secundários e muitas vezes irrelevantes.

A conquista de significações sobre os conhecimentos de um componente curricular, de um tema, de uma unidade didática precisa de um suporte metodológico expressivo e adequado às características do campo epistemológico. Isto significa explorar a especificidade do conhecimento e do conteúdo. Tempos, espaços e culturas diferentes tiveram, têm e terão concepções variadas sobre campos epistemológicos, suas funções, práticas e, portanto, valores atribuídos ou ligados a eles. Não são questões imutáveis.

\section{Intencionalidades}

A educação superior orientada para a profissionalização tem a função de desenvolver a personalidade do estudante como um todo, de desenvolver faculdades/capacidades indispensáveis ao profissional de qualquer campo científico, ou seja, por exemplo, as faculdades/capacidades de percepção, de comunicação, de autodisciplina, de trabalho em equipe, de discernimento, análise, síntese, de elaboração pessoal, de avaliação, de desembaraço, de autoconfiança, de autonomia, de criatividade, de senso crítico, de senso de responsabilidade de valores, princípios éticos etc. Trata-se de uma didática específica que tem como objeto de estudo o ensino "de" no sentido de transformar o pensar e o agir do futuro profissional em um novo contexto, resultante de mudanças socioeconômicas, culturais e tecnológicas. As didáticas específicas veem-se, pois, diante de um desafio que, sem dúvida, apresentam-se como uma prática efetiva e consistente de ensino de graduação em campos específicos e diversificados. É importante promover, de modo mais amplo 
e democrático, uma educação superior de qualidade.

\section{Proposições metodológico- procedimentais}

Diversas são as possibilidades metodológicas e tecnológicas para a elaboração das didáticas específicas, em que professores e estudantes possam dialogar, problematizar e atualizar as questões e desafios dos saberes de um determinado campo epistemológico, uma vez que eles são protagonistas na construção do conhecimento. A capacidade metodológica forma parte dos saberes que estruturam as didáticas específicas e que todo professor universitário deve possuir, no sentido de adotar procedimentos metodológicos não lineares, em que a centralidade da sua ação didática está no estudante. Nesse sentido, vale o registro de Zabalza (2007) de que é fundamental para o docente universitário escolher:

[...]As modalidades metodológicas as que podem desenvolver o ensino são múltiplas. [...]Mas o importante é ser consciente de que cada método ou modalidade metodológica apresenta suas vantagens e inconvenientes. Não existe o melhor método, se não aquele que se ajustar às condições de nossos objetivos formativos, ao conteúdo que vamos trabalhar, às características de nossos alunos, às particularidades de tempo, espaço e recursos que temos de mover. (p. 110).

É necessário, portanto, que o professor reflita e associe, constantemente, teoria e prática, analisando-as com bases nas teorias que fundamentam os campos epistemológicos e pedagógicos e as experiências do trabalho docente e profissional.

\section{Conclusão}

O presente texto teve como objetivo analisar as concepções de Didática Geral e didáticas específicas bem como compreender seus elementos estruturantes. O contato com o referencial teórico consultado permitiu entender melhor o processo de construção de didáticas especiais, ora consolidando certezas, ora apresentando outras dúvidas e questionamentos.

O que fica claro nessa trajetória reflexiva é que, apesar dos diversos avanços da ciência, ainda há uma tímida ação por parte das instituições de educação superior no sentido de estimular o professor a criar novos saberes e novas formulações didáticas. Existe a necessidade de serem delineadas os reais significados das Didáticas Geral e didáticas específicas, uma vez que por meio delas podemos caracterizar os seus elementos estruturantes.

Algumas características das didáticas especiais foram elaboradas a partir de estudos que possibilitaram a construção de uma série de elementos estruturantes. As reflexões tecidas nas concepções dos autores definiram a constatação de que as Didática Geral e as didáticas específicas representam um dos esteios fundantes provocadores da formação construtiva e incentivadora da produção científica bem como a construção de novos saberes profissionais ao integrar teoria-prática, sujeito-objeto, professor-aluno, ensino -aprendizagem, entre outras.

Diante disto, a existência da Didática Geral e das didáticas específicas podem ser apresentadas como um desafio a todos os envolvidos com a educação superior. Ao mesmo tempo, essas didáticas são caminhos para a construção de um processo formativo-investigativo mais democrático integrativo e interdependente. 


\section{Referências}

BARTH, B. M. O saber em construção: para uma pedagogia da compreensão. Lisboa: Instituto Piaget, 1997.

CHARLOT, B. Da relação com o saber: elementos para uma teoria. Porto Alegre: Artes Médicas Sul, 2000.

LIBÂNEO, J. C. Didática e epistemologia: para além do debate entre a didática e as didáticas específicas. In: Veiga, I. P. A. e D’AVILA, C. M. (Orgs.) Profissão docente: Novos sentidos, novas perspectivas. Campinas: Papirus, 2008.

ROLDÃO, M. do C. Professores para que? Para uma reconceitualização da formação de profissionais de ensino. Revista Discursos: perspectivas em educação. Braga, PT: Universidade do Minho, nº 2, 95-120. 2004.

ZABALZA, M. A. O ensino universitário: seu cenário e seus protagonistas. Porto Alegre: Artmed, 2004. 